\title{
Comparação entre a investigação direta da água subterrânea e radar de penetração no solo (GPR) na área do aterro sanitário de Cuiabá (MT)
}

\author{
Aldecy de Almeida Santos ${ }^{1}$, Shozo Shiraiwa ${ }^{2}$, Alexandra Natalina de Oliveira Silvino ${ }^{1}$, \\ Welitom Ttatom Pereira Silva ${ }^{3}$, Neli Assunção Silva ${ }^{1}$, Alexandre Silveira ${ }^{4}$ \& \\ Renato Blat Migliorini ${ }^{5}$
}

\begin{abstract}
Resumo O presente trabalho visa comparar a investigação direta da qualidade da água subterrânea (análises físico-químicas e exames microbiológicos) com o levantamento geofísico realizado pelo método de Radar de Penetração no Solo (GPR - Ground Penetrating Radar) na área do aterro sanitário da cidade de Cuiabá, no estado de Mato Grosso. Os métodos geofísicos permitiram identificar fortes indícios de que o subsolo encontrava-se contaminado, devido à alta condutividade elétrica detectado, em boa parte da área, principalmente na região das lagoas de tratamento de lixiviado e nas laterais sul e norte do aterro. Nos locais onde a disposição de resíduos era mais recente, os sinais de contaminação foram mais acentuados, mesmo havendo impermeabilização de base. A contaminação foi confirmada por investigação direta nos poços de monitoramento próximo das células de resíduos. As amostras das águas subterrâneas apresentaram parâmetros de coliformes, cor, turbidez, ferro, chumbo e manganês superiores aos padrões estabelecidos pela Portaria n ${ }^{\circ}$ 518/04 do Ministério da Saúde.
\end{abstract}

Palavras-chave: resíduos sólidos urbanos, lixiviado, geofísica, recursos hídricos.

\begin{abstract}
Comparison of research direct water and ground penetrating radar of the land (GPR) landfield of Cuiabá (MT), Brazil. This study aims to compare the direct investigation quality of groundwater (physical-chemical analyses and microbiological examination) and geophysical survey by means of Ground Penetrating Radar (GPR) in the area of landfill of Cuiabá city state Mato Grosso. The geophysical methods have identified strong evidence that the subsoil had been contaminated by high electrical conductivity found in much of the area, mainly in the area of treatment of manure ponds and the south and north sides of the landfill. Where the deposition of waste was more recent, the signs of contamination were more pronounced, even with the basic sealing. The contamination was confirmed by research in direct monitoring wells near the cells of waste. Samples of groundwater had parameters of coliform, colour, turbidity, iron, lead and manganese above the standards established by Ordinance $n^{\circ} 518 / 04$ of the Ministry of Health.
\end{abstract}

Keywords: urban solid waste, leachate, geophysics, hydro resources.

INTRODUÇÃ̃ As áreas de disposição de resíduos são consideradas, em nível global, como uma das principais fontes potenciais de contaminação de água subterrânea, além de outros tipos de atividades e empreendimentos antrópicos. Em geral, essas fontes de contaminação são: áreas de disposição de resíduos sólidos (urbanos e industriais); lagoas de tratamento de efluentes industriais; disposição de esgotos sanitários; disposição de resíduos radioativos; atividades agrícolas e agropecuárias; vazamento de petróleo e derivados; entre outros (Lago et al. 2006).

O aterro sanitário de Cuiabá recebe todos os resíduos sólidos urbanos gerados pela cidade, o que totaliza cerca de 450 toneladas por dia. A primeira célula de resíduos urbanos e as lagoas de estabilização que não receberam impermeabilização basal são fontes potenciais de contaminação do solo e das águas subterrâneas pelo lixiviado que apresenta altas concentrações de matéria orgânica, substâncias inorgânicas (metais pesados), concentrações elevadas de sólidos totais, sólidos dissolvidos e de nitrogênio na forma amoniacal, entre outros (Santos 2008).

De acordo com Torres et al. (1997), pelo fato do lixiviado conter, na maioria dos casos, altos níveis de metais e outros compostos que podem ser considerados água residuária industrial, sendo que sua composição muda de um aterro para outro, em função da qualidade e características dos resíduos sólidos depositados, bem

1 - Programa de Pós-Graduação em Física Ambiental- PGFA, Instituto de Física-IF, Universidade Federal de Mato Grosso - UFMT, Cuiabá

(MT), Brasil.E-mail: aldecy_allmeida@yahoo.com.br; lekaesa@gmail.com; nelhy3@hotmail.com

2 - IF, Universidade Federal de Mato Grosso - UFMT, Cuiabá (MT), Brasil. E-mail: shozo@ufmt.br

3 - Programa de Pós-Graduação em Tecnologia Ambiental e Recursos Hídricos, Faculdade de Tecnologia, Universidade de Brasília, Brasília (DF), Brasil. E-mail: wttatom@terra.com.br

4 - Departamento de Engenharia Sanitária e Ambiental, Faculdade de Arquitetura, Engenharias e Tecnologia, UFMT, Cuiabá (MT), Brasil.

E-mail: alexandresilveira@ufmt.br

5 - Departamento de Geologia Geral, Instituto de Ciência Exatas e da Terra, UFMT, Cuiabá (MT), Brasil. E-mail: rena@ufmt.br 
como pelas condições climáticas que influenciam no processo de degradação dos resíduos.

Os métodos geofísicos são uma alternativa no diagnóstico de áreas contaminadas, devido à rapidez e o baixo custo em estudos ambientais. Essa ferramenta pode auxiliar na detecção e no monitoramento de áreas contaminadas, em conjunto com métodos diretos de investigação, como poços de monitoramento.

De acordo com Porsani (1999), a partir de 1990, com o avanço tecnológico, o GPR passou a ser utilizado numa gama maior de problemas, incluindo a localização da pluma de contaminação em áreas impactadas pela disposição de resíduos.

Este estudo teve como objetivo comparar a qualidade das águas subterrâneas na área de influência do aterro sanitário de Cuiabá, por meio de investigação direta, com análises físico-químicas e exames bacteriológicos e o levantamento geofísico de radar de penetração no solo realizados por Laureano (2007).

MATERIAIS E MÉTODOS A seguir encontra-se apresentada uma descrição da metodologia utilizada para o desenvolvimento do trabalho sob a forma dos seguintes itens: caracterização da área de estudo, método de investigação indireta (método GPR) e método de investigação direta (monitoramento da água subterrânea).

Caracterização da área de estudo $\mathrm{O}$ aterro sanitário localiza-se a nordeste da área urbana do município de Cuiabá no Estado de Mato Grosso, conforme apresentado na figura 1. A área do aterro está compreendida entre as coordenadas $56^{\circ} 0^{\prime} 50^{\prime \prime}$ e $56^{\circ} 1^{\prime} 40^{\prime \prime} \mathrm{W}, 15^{\circ} 29^{\prime} 10^{\prime \prime}$ e $15^{\circ} 30^{\prime} 0^{\prime \prime}$ 'S, possuindo aproximadamente de 15,16 ha, localizando-se próximo ao Ribeirão do Lipa (RL), Córrego Doutor (DR) e o Córrego Três Barras (TR), todos pertencentes à Bacia do Rio Cuiabá.

Método GPR O GPR é um método eletromagnético que emprega ondas de rádio em frequências muito altas (normalmente entre $10-1000 \mathrm{MHz}$ ) para localizar estruturas e feições geológicas rasas de subsuperfície ou localizar objetos enterrados pelo homem (Davis \& Annan 1989, Annan \& Cosway 1992).

A técnica empregada por Laureano (2007) no aterro sanitário de Cuiabá, consistiu no levantamento de dois perfis (linha 2 e 9) com afastamento constante, utilizando antenas não blindadas de $50 \mathrm{MHz}$, conforme observado na figura 2.

Para aquisição dos perfis foi mantido o espaçamento constante de dois metros entre as antenas transmissora e receptora. A linha 2 possui $130 \mathrm{~m}$ de comprimento e foi adquirida no sentido de sudoeste para nordeste. E a linha 9 possui $580 \mathrm{~m}$ de comprimento e foi adquirida no sentido de nordeste para sudoeste. A linha 9 foi dividida em três trechos: o primeiro de 0 a $180 \mathrm{~m}$; o segundo de 180 a $360 \mathrm{~m}$; e o terceiro de 400 a $580 \mathrm{~m}$.

Monitoramento da água subterrânea No período de estudo foram avaliados cinco poços de monitoramento distribuídos pela área do aterro (Fig. 3).
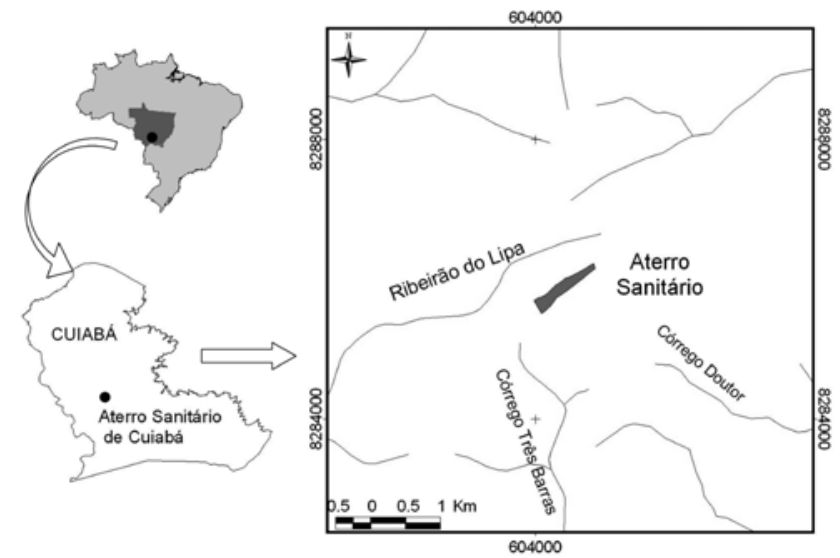

Figura 1 - Localização da Central de Disposição Final de Resíduos Sólidos Urbanos de Cuiabá.

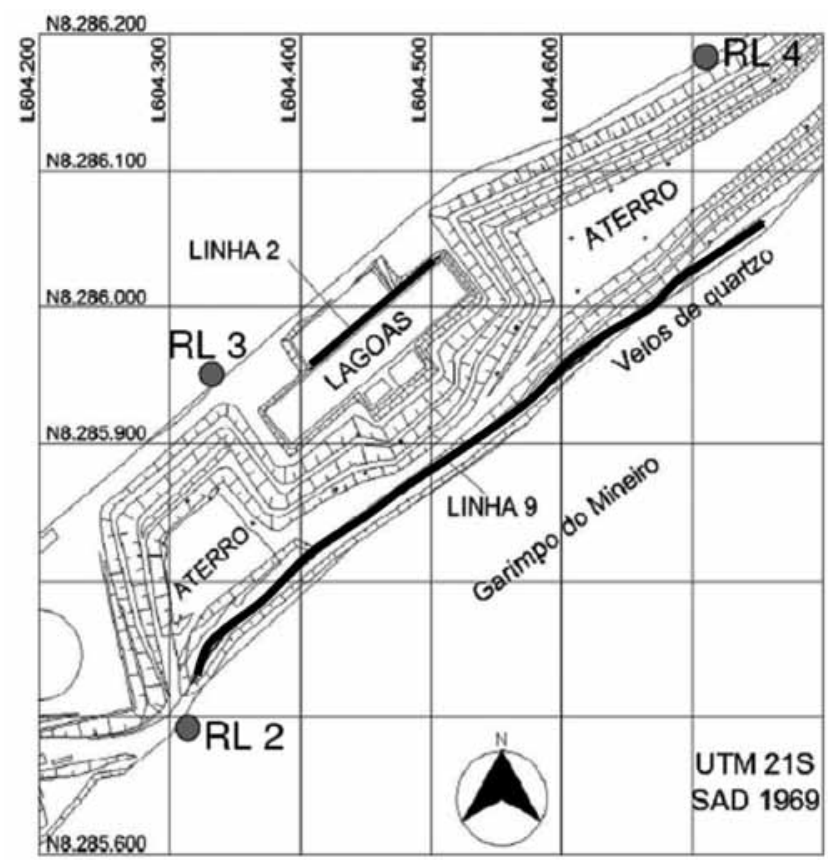

Figura 2 - Localização das linhas 2 e 9. Fonte: Laureano (2007)

O procedimento de amostragem foi realizado de acordo com a NBR 13.895/97, referente à construção de poços de monitoramento, esgotamento, coleta e preservação de amostras.

As coletas dos poços de monitoramento ocorreram entre os meses de outubro de 2006 a outubro de 2007.

Os poços possuem as seguintes características: RL1 - poço tubular profundo de abastecimento e monitoramento; RL2 e RL3 - são poços rasos com aproximadamente 30 metros de profundidade que se situam próximo à célula $1 ;$ RL4 - está próximo à célula $2 ; \mathrm{e} \mathrm{DR}$ 1 - poço tubular profundo monitorado na área adjacente ao aterro que foi utilizado como background, ou branco.

A coleta de amostra de água subterrânea dos poços de monitoramento foi realizada com auxílio do 


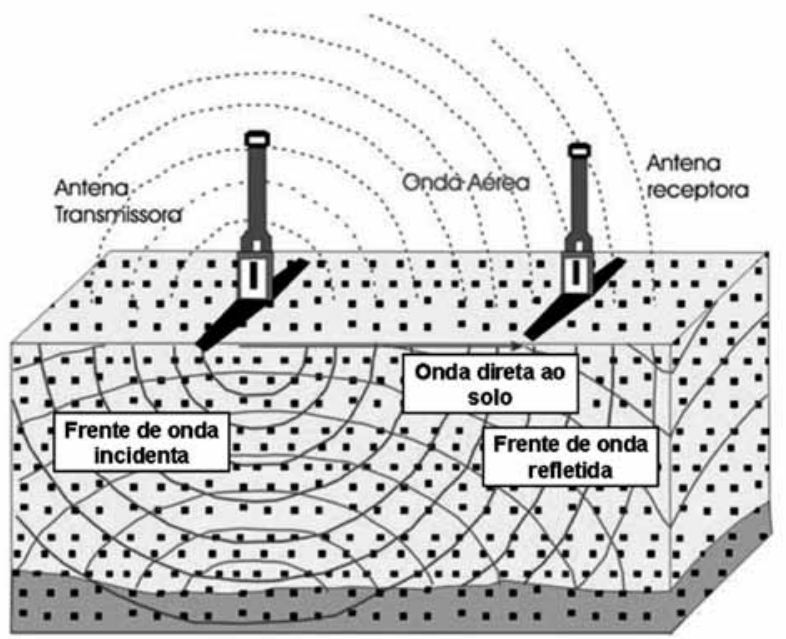

Figura 3 - Localização dos poços de monitoramento. Fonte: Modificado de Laureano (2007)

coletor constituído de um tubo de PVC preto, medindo 0,60 metros de comprimento e 2 polegadas de diâmetro, com uma válvula de retenção vertical instalada em uma das extremidades e na outra um cordão de nylon com 60 metros de comprimento.

As coletas de água para análises físico-químicas (cor, turbidez, $\mathrm{DBO}_{5}, \mathrm{DQO}$ ) e metais (chumbo, ferro e manganês) nos poços foram realizadas utilizando frascos de um litro e para coleta bacteriológica (coliformes totais e Escherichia Coli) frascos de $250 \mathrm{ml}$ esterilizados em laboratório.

Buscou-se preservar as amostras conservando-as em temperatura com aproximadamente $4^{\circ} \mathrm{C}$ até a fase de análises laboratoriais, realizadas no Departamento de Engenharia Sanitária e Ambiental e no Departamento de Química da Universidade Federal de Mato Grosso.

O tabela 1 apresenta a metodologia utilizada nas amostragens da qualidade da água.

Tabela 1 - Métodos de análises físico-químicas metais e bacteriológicas dos pontos de amostragens.

\begin{tabular}{l|c}
\hline \multicolumn{1}{c|}{ Variáveis } & Métodos \\
\hline $\mathrm{pH}$ & Eletrométrico \\
\hline $\mathrm{Cor}$ & Colorimétrico \\
\hline Turbidez & Nefelométrico \\
\hline $\mathrm{DBO}_{5}$ & Iodométrico \\
\hline $\mathrm{DQO}$ & Refluxo fechado - Titulométrico \\
\hline Chumbo & $\begin{array}{c}\text { Espectrofotometria de Absorção } \\
\text { Atômica }- \text { EAA }\end{array}$ \\
\hline Ferro & $\begin{array}{c}\text { Espectrofotometria de Absorção } \\
\text { Atômica }- \text { EAA }\end{array}$ \\
\hline Manganês & $\begin{array}{c}\text { Espectrofotometria de Absorção } \\
\text { Atômica }- \text { EAA }\end{array}$ \\
\hline $\begin{array}{l}\text { Coliformes totais e } \\
\text { Escherichia Coli }\end{array}$ & Colilert - (ONPG/MUG) \\
\hline
\end{tabular}

RESULTADOS E DISCUSSÃO Os perfis de GPR das linhas 2 e 9 foram obtidos através de ensaios geofísicos, conforme editado e apresentados nas figuras 4 e 5 , nas quais verificou-se possíveis zonas de contaminação.

O perfil da linha 2, representado na figura 4, mostrou ausência de reflexão, denominada de zona de sombra (shadow zone) de 25 a $150 \mathrm{~m}$, indicando contaminação do subsolo, pois a alta condutividade atenuou o sinal significativamente.

A zona de sombra da linha 2 iniciou-se numa faixa de 5-6 $\mathrm{m}$ de profundidade, abaixo da linha azul da figura 4. Ou seja, logo abaixo do fundo das lagoas, indicando que a ausência de impermeabilização está possibilitando a percolação de lixiviado para o subsolo (Laureano \& Shiraiwa 2008).

As outras linhas da figura 4 (verde, laranja, rosa e amarela) são ondas aéreas, que foram refletidas em obstáculos presentes na área tais como as paredes laterais das lagoas facultativas e o paredão de lixo ao redor da linha.

A análise da água do poço de monitoramento RL3, localizado próximo da linha 2 do GPR, confirmou a contaminação indicada pelo método GPR, provavelmente da Célula 1 e da lagoa de estabilização. Os valores médios de metais detectados (manganês: $0,135 \mathrm{mg} / \mathrm{L}$, chumbo: $0,017 \mathrm{mg} / \mathrm{L}$, ferro: $7,73 \mathrm{mg} / \mathrm{L}$ ), cor: $299 \mathrm{mgPt}-\mathrm{Co}_{\mathrm{L}} \mathrm{L}^{-1}$, turbidez: $64 \mathrm{uT}$, coliformes totais: $5,0 \mathrm{E}+4 \mathrm{NMP} / 100 \mathrm{~mL}$ e Escherichia Coli: $25 \mathrm{NMP} / 100 \mathrm{~mL}$ apresentaram valores superiores ao preconizado na Portaria $\mathrm{n}^{\circ}$ 518/04 e do poço Background (DR 1). De acordo com Feitosa e Filho (2000) valores superiores a $1 \mathrm{mg} / \mathrm{L}$ de $\mathrm{DBO}_{5}$ e a $10 \mathrm{mg} / \mathrm{L}$ de DQO, indicam contaminação da água subterrânea. Os valores médios de $\mathrm{DBO}_{5}(22 \mathrm{mg} / \mathrm{L})$ e $\mathrm{DQO}(46 \mathrm{mg} / \mathrm{L})$ obtidos no poço RL3 indicam uma forte contaminação, muito superior ao poço background (DR 1).

O poço RL4 apresentou uma forte contaminação oriunda da Célula 2 do aterro, refletindo na qualidade da água subterrânea, conforme indicado pelo método geofísico. A concentração de ferro foi 49 vezes superior ao valor máximo preconizado na Portaria $\mathrm{n}^{\mathrm{o}} 518 / 04$. O manganês e chumbo também apresentaram valores médios de $0,034 \mathrm{mg} / \mathrm{L}$ e $0,018 \mathrm{mg} / \mathrm{L}$, respectivamente, acima do preconizado na referida Portaria. Os valores de $\mathrm{pH}$ do poço $\mathrm{RL} 4$ variaram entre 5,4 e 5,7, inferiores ao preconizado pela Portaria $n^{\circ}$ 518/04. Em relação ao resultado médio obtido de cor (343 mgPt-Co.L $\left.\mathrm{L}^{-1}\right)$, turbidez (84 uT), coliformes totais $(11 \mathrm{E}+4 \mathrm{NMP} / 100 \mathrm{~mL})$ e Escherichia Coli $(94$ NMP $/ 100 \mathrm{~mL}$ ) estão acima do valor preconizado pela Portaria ${ }^{\circ} 518 / 04$. O poço RL4 apresentou contaminação referente à matéria orgânica $\mathrm{DBO}_{5} \mathrm{e} \mathrm{DQO}$ com valor médio de 35 e $69 \mathrm{mg} / \mathrm{L}$.

A figura 5 apresenta os perfis de GPR da linha 9 , no trecho de 400 a $570 \mathrm{~m}$ que se situa no lado sul do aterro, ao lado do Garimpo do Mineiro e próximo ao poço RL2. Os dados mostraram ausência de reflexão em determinados trechos, abaixo da linha azul que representam zonas de sombra, onde o sinal é fortemente atenado a área contaminada pela alta condutividade elétrica do meio e repercutam na maior parte do perfil abaixo de $14 \mathrm{~m}$ de profundidade. 


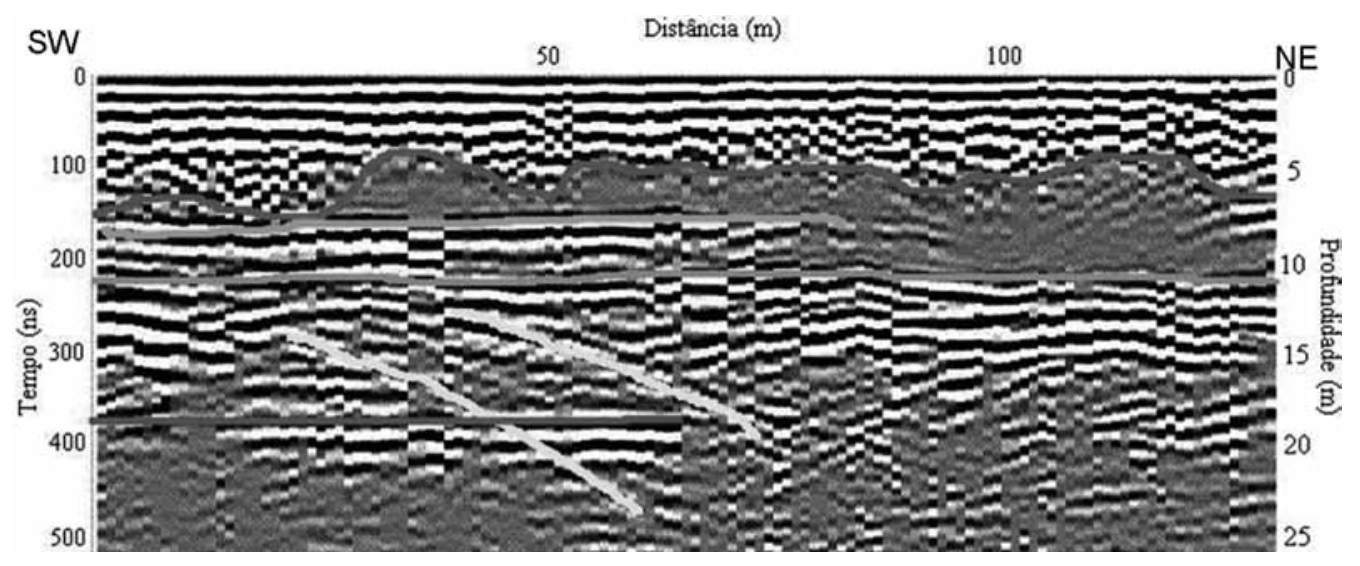

Figura 4 - Perfil de GPR da linha 2 - antena de $50 \mathrm{MHz}$. Fonte: Laureano (2007)

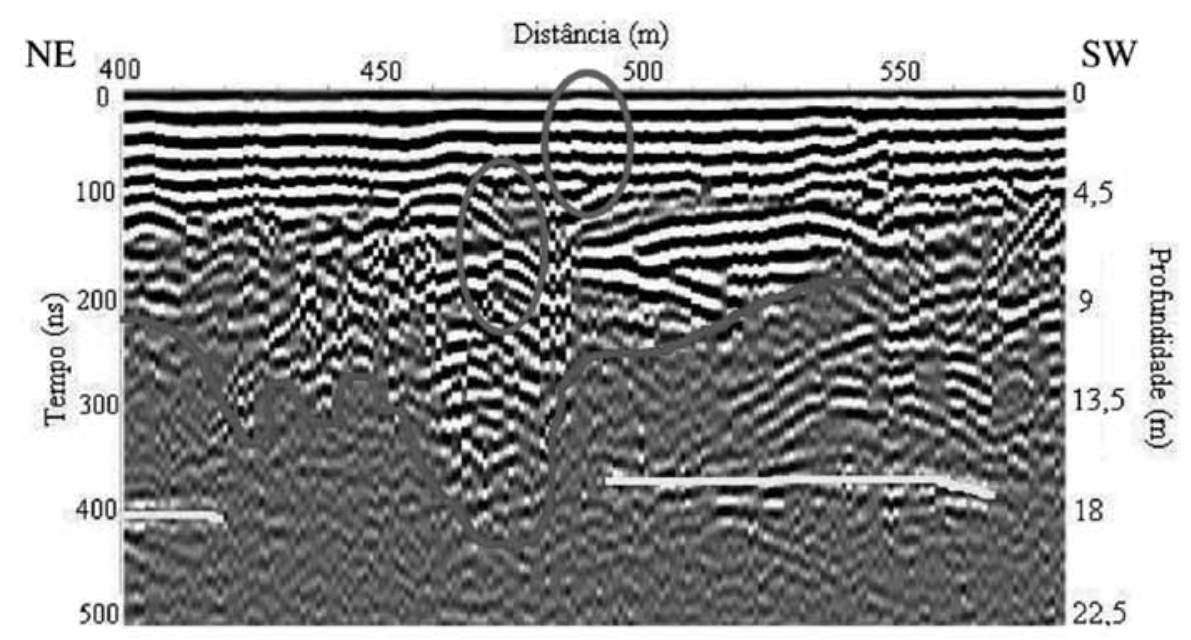

Figura 5 - Perfil de GPR da linha 9 - antena $50 \mathrm{MHz}$. Fonte: Laureano (2007)

No início do perfil (0 a $50 \mathrm{~m}$ ) visualizam-se um padrão irregular devido aos veios de quartzo vertical presentes na área. A linha azul do perfil da figura 5 são refletores que representam as camadas e rocha e as regiões internas às elipses vermelhas representam feições locais.

De acordo com Laureano (2007) as linhas amarelas são ondas aéreas e representam refletores localizados de 45 a 60 m de distância da linha 9 e correspondem ao paredão do Garimpo do Mineiro, que é relativamente paralelo à linha 9 . Na posição $550 \mathrm{~m}$ localiza-se o poço RL2 onde as análises químicas da água mostram um alto grau de contaminação e poluição oriunda do lixiviado da Célula 1.

As análises da água do poço RL2 mostram a contaminação por manganês $(0,104 \mathrm{mg} / \mathrm{L})$, chumbo $(0,015 \mathrm{mg} / \mathrm{L})$ e ferro $(4,67 \mathrm{mg} / \mathrm{L})$. A cor e a turbidez apresentaram valores médios de $169 \mathrm{mgPt}-\mathrm{Co} . \mathrm{L}^{-1} \mathrm{e} 21$ uT, DQO de $20 \mathrm{mg} / \mathrm{L}$ e $\mathrm{DBO}_{5}$ de $7 \mathrm{mg} / \mathrm{L}$, coliformes totais com média geométrica de $919 \mathrm{NMP} / 100 \mathrm{~mL}$ e
Escherichia Coli de $21 \mathrm{NMP} / 100 \mathrm{~mL}$.

No resultado do poço de monitoramento RL1, somente os coliformes totais e Escherichia Coli apresentaram média superiores à Portaria $n^{\circ}$ 518/04 com valores de 51 e $1 \mathrm{NMP} / 100 \mathrm{~mL}$, respectivamente.

CONCLUSÕES As análises físico-químicas e metais da água subterrânea confirmam a existência da contaminação, observadas nos locais indicados pelos resultados geofísicos, evidenciando a importância do uso de geofísica na detectação de alterações anômalas de aterro sanitário.

Os resultados obtidos no monitoramento das águas subterrâneas apresentaram contaminação próxima às células (não impermeabilizada e impermeabilizada) apresentando elevado teor de matéria orgânica, coliformes totais e Escherichia Coli, cor, turbidez, ferro, manganês e chumbo, superiores aos padrões estabelecidos pela Portaria do Ministério da Saúde nº 518/04. 
Agradecimentos Ao Programa de Pós Graduação em Física Ambiental, ao Departamento de Engenharia Sanitária e Ambiental, à Universidade Federal de Mato Grosso - UFMT, pelo apoio logístico e ao CNPq - Con- selho Nacional de Desenvolvimento Científico e Tecnológico e à Capes- Coordenação de Aperfeiçoamento de Pessoal de Nível Superior pelo apoio financeiro.

\section{Referências}

Annan A.P. \& Cosway SW. 1992. Ground penetrating radar survey design. In:AGEEP, Symposium on the Application of Geophysics to Engineering and Environmental Problems, 5, Oakbrook, Illinois, Proceedings, 2: 329352

ASSOCIAÇAO BRASILEIRA DE NORMAS TÉCNICAS. 1997. NBR 13895 - Construção de poços de monitoramento e amostragem. Rio de Janeiro

Davis JL \& Annan AP. 1989. Ground Penetrating Radar for High Resolution Mapping of oil and rock stratigraphy. Geophysical Prospecting, 37:531-551.

Lago A.L, Elis V.R, Giacheti H.L. 2006. Aplicação de métodos geofísicos em uma área de disposição de resíduos sólidos urbanos em Bauru-SP. Revista Brasileira de Geofísica, 24:357-374.

Laureano A.T. 2007. Estudos geofísicos no aterro sanitário de Cuiabá-MT. Dissertação de Mestrado, Programa de Pós-Graduação em Física e Meio Ambiente, Instituto de Ciências Exatas e da Terra, Universidade Federal do Mato Grosso, 149p.

Laureano A.T. \& Shiraiwa S. 2008. Ensaios geofísicos no aterro sanitário de Cuiabá-MT. Revista Brasileira de Geofísica, 26:173-180.

Moreira C.A., Dourado J.C., Braga A.C.O. 2006. Aplicação da técnica de caminhamento elétrico em área contaminada por derivados de petróleo. Revista Brasileira de Geofisica, 24:383-392.

Feitosa F.A.C. \& Manoel Filho J. 2000. Hidrologeologia. Conceitos e Aplicações. Fortaleza, CPRM, LABHIDUFPE, $391 \mathrm{p}$.

Porsani J.L. 1999. Ground Penetrating Radar (GPR): Proposta metodológica de empregoem estudos geológicogeotécnicos nas regiões de Rio Claro e Descalvado, SP. Tese de doutoramento, Programa de Pós-Graduação em Geociências, Instituto de Geociências e Ciências Exatas, Universidade Estadual Paulista, 159 p.

Santos A.A. 2008. Qualidade das águas superficiais e subterrâneas na área de influência do aterro sanitário de Cuiabá. Dissertação de Mestrado. Programa de Pósgraduação em Física e Meio Ambiente. Instituto de Ciências Exatas, Universidade Federal de Mato Grosso, $112 \mathrm{p}$.

Torres P., Barba L.E., Riascos J., Vidal J.C. 1997. Tratabilidade biológica de chorume produzido em aterro não controlado. Revista de Engenharia Sanitária $e$ Ambiental, 2:55-62.

Manuscrito ID 11778

Submetido em 16 de julho de 2008 Aceito em 17 de dezembro de 2009 